Check for updates

Cite this: Mater. Horiz., 2020, 7, 1631

Received 28th January 2020, Accepted 3rd April 2020

DOI: $10.1039 / \mathrm{dOmh00141d}$

rsc.li/materials-horizons

\section{Key role of the meniscus shape in crystallization of organic semiconductors during meniscus-guided coating $\dagger$}

\author{
Ke Zhang, ${ }^{a}$ Zuyuan Wang, ${ }^{a}$ Tomasz Marszalek, (D) ${ }^{\text {ab }}$ Michal Borkowski, ${ }^{b}$ \\ George Fytas, ${ }^{a}$ Paul W. M. Blom (D) and Wojciech Pisula (D)*ab
}

\begin{abstract}
Solution processable organic semiconductors (OSCs) hold advantages for the fabrication of flexible and large-area electronic devices. Meniscus-guided coating (MGC) is one promising technique to tune the crystallization and thin film morphology of OSCs. In this work, we demonstrate the crucial role of the meniscus shape in the fluid flow and crystallization of OSCs during MGC. We demonstrate that angle-dependent dip-coating (ADDC) allows precise control of the meniscus shape. The use of a small meniscus angle during ADDC of 2,7-dioctyl[1]benzothieno[3,2-b][1]benzothiophene (C8-BTBT) enhances the crystallization and mass deposition of the OSC due to an increased upward fluid flow. The resulting aligned crystalline film with high surface coverage favors the charge carrier transport in C8-BTBT based field-effect transistors. This work provides comprehensive insight into the fundamental mechanism of OSC crystallization during MGC, which is important for the large-area deposition of OSCs for practical electronic applications.
\end{abstract}

\section{Introduction}

Solution processable organic semiconductors (OSCs) are promising for large area, lightweight, and flexible electronics, such as organic field-effect transistors (OFETs). ${ }^{1-3}$ Control over the morphology and molecular packing of OSCs is crucial to realize excellent charge carrier transport in OFETs. ${ }^{4,5}$ Meniscus-guided coating (MGC), ${ }^{6}$ including dip-coating, ${ }^{7}$ zone-casting, ${ }^{8}$ bladecoating, ${ }^{9}$ and solution shearing, ${ }^{10}$ provides an efficient way to grow OSCs into highly crystalline thin films. Among various MGC techniques, dip-coating is an excellent approach to precisely control the film thickness with minimal solution waste. ${ }^{11}$ Homogeneous monolayers based on conjugated polymers have

\footnotetext{
${ }^{a}$ Max Planck Institute for Polymer Research, Ackermannweg 10, Mainz 55128, Germany.E-mail: pisula@mpip-mainz.mpg.de

${ }^{b}$ Department of Molecular Physics, Faculty of Chemistry, Lodz University of Technology, Zeromskiego 116, Lodz 90-924, Poland

$\dagger$ Electronic supplementary information (ESI) available. See DOI: 10.1039/ d0mh00141d
}

\begin{abstract}
New concepts
Meniscus-guided coating is an attractive technique to deposit thin films of organic semiconductors for electronic devices, but only little insight into the fundamental principles of the fluid mechanics for the crystal growth and film formation has been so far provided. In this work, angle-dependent dip-coating is demonstrated as a novel key concept to control the meniscus shape and to modulate the film growth and morphology of solution processable semiconductors in a convenient and efficient way. As the main conceptual approach, the shape of the meniscus is adjusted by tuning the deposition angle of the solution on the moving substrate. Comprehensive insights into the fluid dynamics during dip-coating are gained from the combination of experimental results and steady-state simulations. It is observed that at small meniscus angle the concentration gradient and mass deposition of the solute are increased, leading to improved film morphology and charge carrier transport in field-effect transistors. Angle-dependent meniscus-guided coating as a new concept for semiconductor materials and understanding the relation between film formation and fluid mechanics are important for scaling-up solution processing techniques for practical applications of electronic technologies.
\end{abstract}

been fabricated for OFET applications through careful control of the withdrawal speed of the substrate and the concentration of the solution. ${ }^{12,13}$ In the case of small molecule OSCs, the dip-coated films are prone to structural defects, such as nonuniform morphology, void formation, and dendritic growth, due to the limited-mass-transport. ${ }^{14-16}$

According to the relation between the coating speed and the resulting film thickness, MGC is classified into two deposition regimes, evaporation (or capillary) and Landau-Levich (or Landau-Levich-Derjaguin), with an additional transition region as the mixed regime. ${ }^{6}$ In addition, the evaporation rate $(\nu)$ and coating speed during MGC significantly influence the crystal growth of OSCs. For instance, fast evaporation of low boiling point solvents can improve the growth of crystalline acene films during dip-coating. ${ }^{17}$ A predictive model for the equilibrium coating speed for solvents of different boiling points and substrate temperatures is proposed.$^{18}$ Furthermore, mixed solvents permit tuning the solubility, nucleation rate and crystallization of OSCs. ${ }^{15,19}$ The wettability and surface energy 
of the substrate also play a critical role in determining the nucleation and crystal growth of OSCs during MGC. ${ }^{20,21}$

Recently, a broad variety of MGC methods have been developed to more precisely control the nucleation and crystal growth of small molecule and polymer OSCs to further improve the charge carrier transport. $^{4,22}$ Solution shearing using a micropillar-pattered blade enhances the mass transport during coating by re-directing the fluid flow. In this way, the dendritic crystal growth of 6,13-bis(triisopropylsilylethynyl)pentacene (TIPS-pentacene) was transformed into large domains of millimeter-size. ${ }^{10}$ Bi-phasic dipcoating allows depositing films from a small solution volume even at limited solubility of the OSC. ${ }^{23,24}$ Template-assisted blade-coating can reduce the free energy barrier for polymer crystallization to attain alignment. ${ }^{25}$ Channel-restricted meniscus self-assembly is attributed to micro-confinement and enables control over the meniscus width, leading to uniform growth of organic crystals. ${ }^{26} \mathrm{~A}$ comprehensive understanding of the crystallization and film growth mechanism of OSCs during MGC is essential for thin film deposition for electronic applications. A firm understanding of the alignment mechanism has been developed, but only little insight into the fundamental principles of the fluid mechanics for the crystal growth of OSCs has been so far provided. A comprehensive study of the relation between the meniscus shape, fluid mechanical process and OSC crystallization during MGC is still required.

In this work, angle-dependent dip-coating (ADDC) is applied for MGC to precisely control the meniscus shape. ${ }^{27}$ The advantage of dipcoating is its simplicity and accurate adjustment of the coating angle as already reported for inorganic sol-gel films. The control over the thickness and homogeneity of the films deposited in the LandauLevich regime was significantly improved at large tilting angles $\alpha$ (Fig. 1a). ${ }^{28}$ The experimental results on ADDC of 2,7-dioctyl[1] benzothieno[3,2- $b][1]$ benzothiophene (C8-BTBT) and two-dimensional fluid simulations reveal that the streamline stagnation point between the upward and recirculation flow is mainly affected by the meniscus shape. A narrow meniscus shape at small angle $\beta$ elevates the evaporation rate $\left(\nu_{\mathrm{m}}\right)$ and upward flow at the meniscus, leading to a larger concentration gradient near the contact line, favoring the crystal growth of the OSC during MGC. This fluid flow assisted crystallization is also favored by higher supersaturation caused by a lower solubility of the OSC. On the other hand, the crystallization is limited on substrates with low surface energy due to an increased nucleation barrier. This work gives a comprehensive insight into the OSC crystallization behavior during MGC taking into account fluid mechanical processes. These findings and conclusions are crucial for the deposition of homogenous and ordered thin films from solution and the up-scaling of the MGC process for practical applications.

\section{Experimental section}

\section{Materials}

C8-BTBT, polystyrene (400 kDa), hexamethyldisilazane (HMDS) and octadecyltrichlorosilane (OTS) are purchased from Sigma and used without further purification.
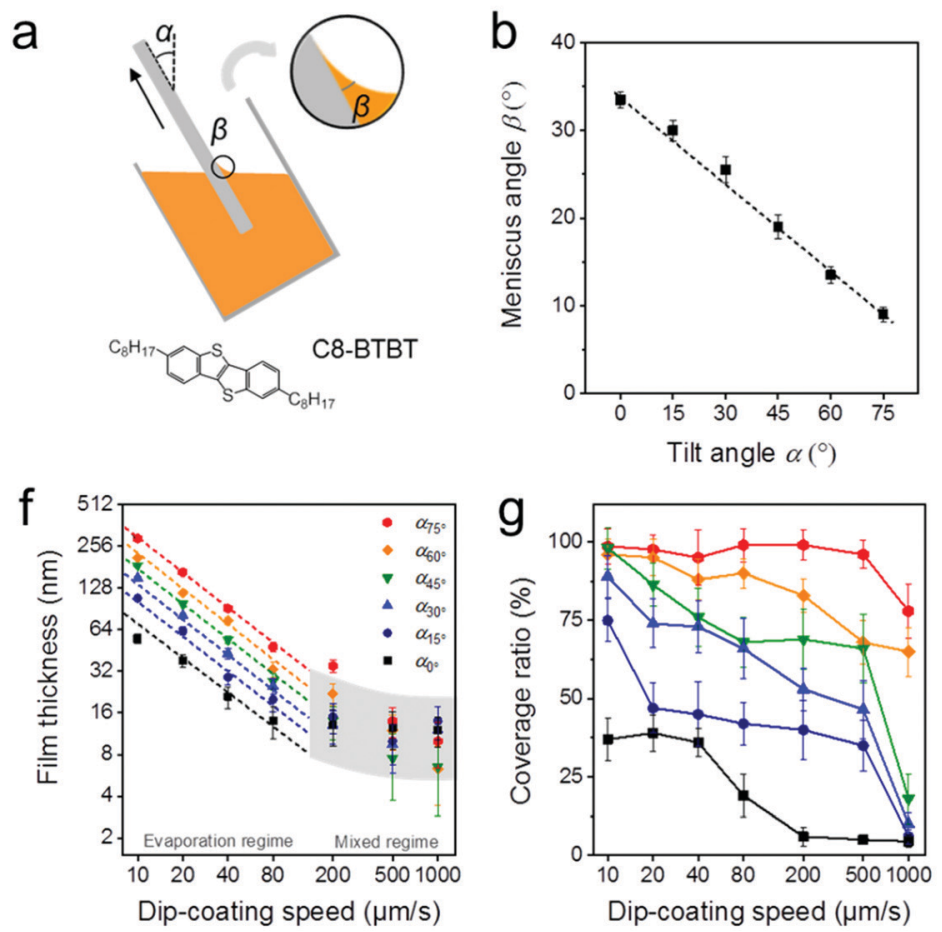

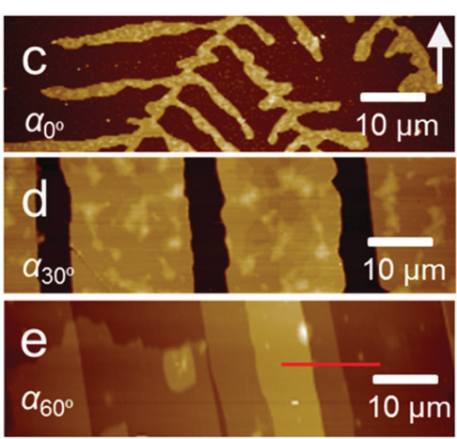

$\mathrm{h}$

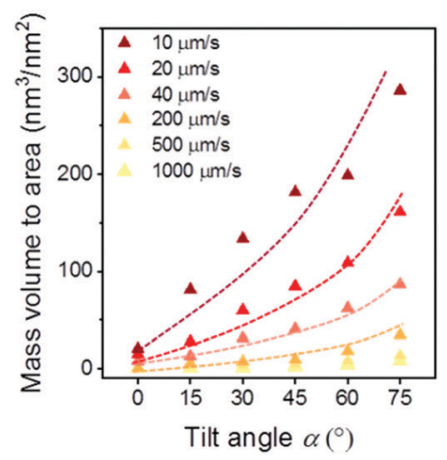

Fig. 1 ADDC of C8-BTBT. (a) Schematic diagram of ADDC and molecular structure of C8-BTBT (black arrow indicates the coating direction). (b) Relation between $\beta_{\mathrm{CHCl}_{3}}$ and $\alpha$. Morphology of C8-BTBT crystals obtained at (c) $\alpha_{0^{\circ}}$, (d) $\alpha_{30^{\circ}}$ and (e) $\alpha_{60^{\circ}}$ by ADDC at $20 \mu \mathrm{m} \mathrm{s}{ }^{-1}$ (the white arrow indicates the coating direction). (f) Film thickness and (g) coverage ratio of C8-BTBT as a function of the dip-coating speed for different $\alpha$. (h) Mass deposition of C8-BTBT for different dip-coating speeds as a function of $\alpha$. 


\section{Angle-dependent dip-coating}

Silicon substrates with a $300 \mathrm{~nm}$ thick $\mathrm{SiO}_{2}$ layer were treated by oxygen plasma at $100 \mathrm{~W}$ for $3 \mathrm{~min}$ to increase the surface energy to around $62-67 \mathrm{mN} \mathrm{m}^{-1}$. In addition, the oxygen plasma treatment is beneficial for a high-quality modification of the $\mathrm{SiO}_{2}$ surface by the OTS and HMDS self-assembled monolayers. Angle-dependent dip-coating of C8-BTBT was performed from a $\mathrm{CHCl}_{3}$ or $\mathrm{CHCl}_{3}$ :hexane solution at a concentration of $3 \mathrm{mg} \mathrm{mL}^{-1}$. The dip-coating speeds ranged from $10 \mu \mathrm{m} \mathrm{s}^{-1}$ to $1000 \mu \mathrm{m} \mathrm{s}^{-1}$, and the substrate tilt angles were tuned from $0^{\circ}$ to $75^{\circ}$ in an ambient atmosphere. The HMDS or OTS self-assembled monolayers were obtained by exposing the silicon wafers to the corresponding silane vapor at $150{ }^{\circ} \mathrm{C}$ for $6 \mathrm{~h}$.

\section{Morphology characterization}

The film morphology was characterized by a Leica POM and a Bruker Dimension Icon FS AFM in tapping mode. Contact angle measurements were performed with a contact angle meter, Data Physics, OCA35. GIWAXS was carried out by means of a solid anode X-ray tube (Siemens Kristalloflex X-ray source, copper anode X-ray tube operated at $35 \mathrm{kV}$ and $40 \mathrm{~mA}$ ), Osmic confocal MaxFlux optics, an X-ray beam with pinhole collimation and a MAR345 image plate detector. Film thickness measurements were performed using a KLA Tencor Profiler and a Bruker Dimension Icon FS AFM. The coverage ratio was characterized using ImageJ.

\section{COMSOL simulation}

Steady-state simulations were conducted by using the COMSOL Multiphysics package. The flow and concentration distributions were captured by using the Creeping Flow and Transport of Dilute Species models. The model dimensions were determined based on the experimentally obtained shape of the meniscus during ADDC.

\section{Charge transport characterization}

A bottom-gate and top-contact configuration was employed for OFET devices. Heavily doped n-type Si wafers were used as a gate electrode and a $300 \mathrm{~nm}$ thick $\mathrm{SiO}_{2}$ layer (capacitance of $11 \mathrm{nF} \mathrm{cm}^{-2}$ ) was adopted as a gate dielectric layer. Source and drain electrodes were deposited at a thickness of $50 \mathrm{~nm}$ by gold evaporation. The transistor channel length and width were $25 \mu \mathrm{m}$ and $500 \mu \mathrm{m}$, respectively. A Keithley 4200-SCS was used for all standard electrical measurements in a glove-box under a nitrogen atmosphere.

\section{Results and discussion}

\section{Angle-dependent dip-coating of C8-BTBT}

During MGC of OSCs, the meniscus refers to the liquid shape between the substrate and coating head or bulk solution, which is determined by a combination of surface tension and external forces (usually gravity). ${ }^{29}$ The meniscus shape is not only influenced by the surface energy of the substrate and the surface tension of the solution, but also depends on the substrate tilt angle $(\alpha)$ during dip-coating (Fig. 1a) or the distance of the coating head to the substrate during slot coating and zone-casting. When an oxygen plasma treated silicon substrate ( $\mathrm{S}_{\text {plasma }}$ ) is immerged into $\mathrm{CHCl}_{3}$, a capillary action occurs at the interface between $S_{\text {plasma }}$ and the bulk solvent and a stable meniscus is achieved immediately. The meniscus angle of $\mathrm{CHCl}_{3}\left(\beta_{\mathrm{CHCl}_{3}}\right)$ decreases from $33-34^{\circ}$ to less than $10^{\circ}$ when $S_{\text {plasma }}$ is tilted from $\alpha_{0^{\circ}}$ to $\alpha_{75^{\circ}}$ (Fig. $1 \mathrm{~b}$ and Fig. S1, ESI $\dagger$ ).

The same meniscus angle is observed for the diluted solution and the pure solvent during dip-coating. ${ }^{30}$ In addition, the meniscus angle is independent of the coating speed in the evaporation regime (coating speed less than $100 \mu \mathrm{m} \mathrm{s}^{-1}$ ), but elongates for high coating speeds in the Landau-Levich regime (coating speed higher than $1000 \mu \mathrm{m} \mathrm{s}^{-1}$ ). ${ }^{31}$ To investigate the role of the meniscus shape in the OSC deposition, C8-BTBT coating was carried out in the evaporation regime by ADDC on $\mathrm{S}_{\text {plasma }}$ from $\mathrm{CHCl}_{3}$. The molecular structure of C8-BTBT is shown in Fig. 1a. Dip-coating was chosen for MGC since it is a relatively facile coating technique and allows precise adjustment of the coating angle. During dip-coating of C8-BTBT at $20 \mu \mathrm{m} \mathrm{s}^{-1}, \beta_{\mathrm{CHCl}_{3}}$ on $\mathrm{S}_{\text {plasma }}$ was precisely controlled by solely varying $\alpha$. At $\alpha_{0}$ o dendritic crystals are grown due to the limitedmass-transport of C8-BTBT (Fig. 1c and 2). ${ }^{14,31}$ When the substrate is tilted to $\alpha_{30^{\circ}}$, the growth of dendritic crystals is suppressed and the film turns into crystalline ribbons aligned in the coating direction (Fig. 1d and 2). This implies enhanced mass transport for the crystal growth caused by the substrate tilting. At further substrate tilting of $\alpha_{60}$, a terrace-like crystalline morphology is formed (Fig. 1e and 2). The height plot along the red line in Fig. 1e exhibits a difference between single terrace steps of around $2.9 \mathrm{~nm}$ corresponding to the molecular length of C8-BTBT and its interlayer distance (Fig. S2a, ESI $\dagger$ ). ${ }^{32}$

During ADDC of C8-BTBT in the speed range from $10 \mu \mathrm{m} \mathrm{s}^{-1}$ to $1000 \mu \mathrm{m} \mathrm{s}^{-1}$, the deposition regimes are characterized by the resulting film thickness. As shown in Fig. 1f, the evaporation regime is established for deposition speeds from $10 \mu \mathrm{m} \mathrm{s}^{-1}$ to $80 \mu \mathrm{m} \mathrm{s}^{-1}$, characterized by a power-law decrease (exponent -1 ) in film thickness corresponding to observations during blade coating of C8-BTBT,${ }^{33}$ while the mixed regime is found between $200 \mu \mathrm{m} \mathrm{s}^{-1}$ and $1000 \mu \mathrm{m} \mathrm{s}^{-1} .{ }^{11}$ Interestingly, in the evaporation regime of ADDC, the film thickness is greatly influenced by $\alpha$. For instance, for a dip-coating speed of $10 \mu \mathrm{m} \mathrm{s}^{-1}$, the film thickness is around $200 \mathrm{~nm}$ at $\alpha_{60^{\circ}}$ and 3.4 times higher than at $\alpha_{0^{\circ}}$ (Fig. 1f and Fig. S2, ESI $\dagger$ ). In addition, the coverage of the crystalline C8-BTBT film also improves with larger $\alpha$ and small $\beta_{\mathrm{CHCl}_{3}}$, as show in Fig. $1 \mathrm{~g}$ and 2. For dip-coating speeds between $20 \mu \mathrm{m} \mathrm{s}^{-1}$ and $500 \mu \mathrm{m} \mathrm{s}^{-1}$, the coverage ratio is below $50 \%$ for $\alpha$ between $0^{\circ}$ and $15^{\circ}$, and increases to above $75 \%$ for $\alpha$ between $60^{\circ}$ and $75^{\circ}$. This behavior is in good agreement with observations for blade-coated nanoparticles. ${ }^{34}$ It was found that a moderately curved meniscus ensures also homogeneous particle film formation. The mass deposition (mass to area) of C8-BTBT for different dip-coating speeds derived from the thickness and coverage ratio implies that a large $\alpha$ enhances the mass transport for the film deposition (Fig. 1h). The improvement in mass 


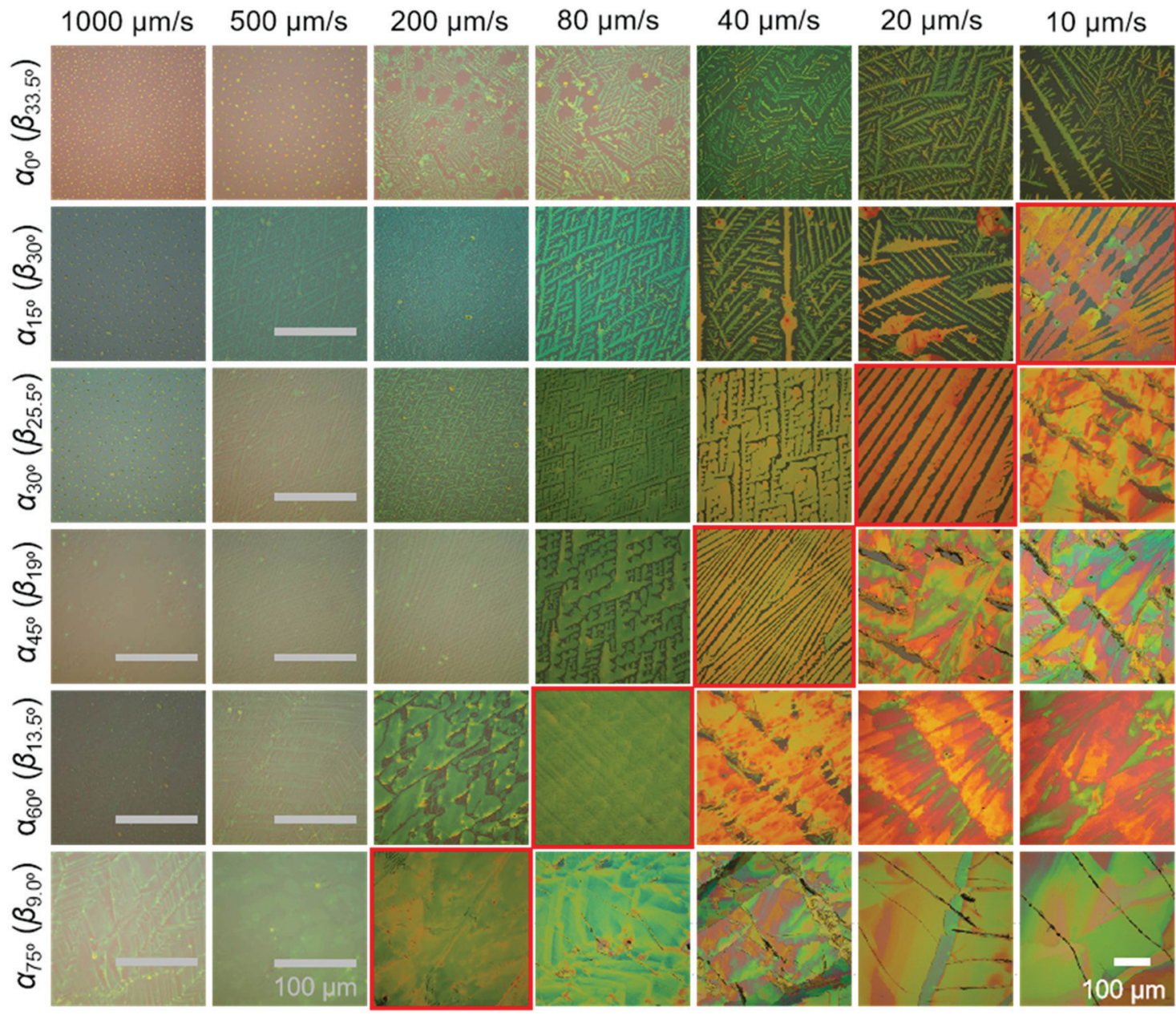

Fig. 2 Optical microscopy images of C8-BTBT film morphologies cast by ADDC at different dip-coating speeds and $\alpha$. The grey and white scale bars represent $100 \mu \mathrm{m}$; the white scale is valid for all images without a bar. Images of aligned crystalline morphologies are indicated by a red frame.

deposition is especially large for small dip-coating speeds. As previously reported for blade-coating, the amount of molecules per unit volume supplied to the meniscus-line region can be also increased by the solute concentration. ${ }^{33}$

The crystalline C8-BTBT films obtained at different dip-coating speeds and $\alpha$ exhibit distinct morphologies, such as crystalline dots, dendrites, ribbons, and slip-stick structures (Fig. 2) ${ }^{14,35}$ Similar types of morphologies were observed for C8-BTBT by varying the boiling point of the solvent during blade coating. ${ }^{33}$ Aligned crystalline ribbons result from balanced-mass-transport at appropriate dipcoating speed and $\alpha$, as highlighted by the red frame of the corresponding optical microscopy images in Fig. 2 and Fig. S2c (ESI $\dagger$ ). Limited-mass-transport in the regimes of elevated dip-coating speed and low $\alpha$ leads to crystal-dots and dendritic growth. On the other hand, in regimes of low dip-coating speed and large $\alpha$, the competition between pinning and depinning forces induces a "stick-slip" morphology with a certain spacing/stripe ratio. ${ }^{6,35}$ The reduced spacing at high $\alpha$ contributes to the raised coverage ratio. It implies that the formation of the stick-slip morphology is subject to the meniscus shape.

Since the thickness of the dip-coated films is proportional to the evaporation rate of the bulk solution $\left(\nu_{\mathrm{bulk}}\right),{ }^{11} \nu_{\operatorname{bulk}(\alpha)}$ was measured to clarify its influence on the film thickness at various $\alpha$ (Fig. S3, ESI $\dagger$ ). During ADDC of C8-BTBT from a not completely solvent filled vial $(15 \mathrm{~mL}), \nu_{\operatorname{bulk}\left(75^{\circ}\right)}$ is around 2.3 times larger than $\nu_{\operatorname{bulk}\left(0^{\circ}\right)}$ at $\alpha_{0^{\circ}}$ (Fig. S4, ESI $\dagger$ ), wherein this difference (varied $\nu_{\operatorname{bulk}(\alpha)}$ ) is attributed to the change of the liquid level during tilting the vial (Fig. 1a). On the other hand, the film thickness at $\alpha_{75^{\circ}}$ is 4.5 times higher than at $\alpha_{0^{\circ}}$ (Fig. S4, ESI $\dagger)$, and thus different from the $\nu_{\operatorname{bulk}\left(75^{\circ}\right)} / \nu_{\operatorname{bulk}\left(0^{\circ}\right)}$ ratio, indicating a substantial impact of the meniscus shape on the mass deposition during ADDC.

\section{Fluid flow simulation}

To better understand the role of the meniscus shape in the film formation during MGC, the fluid mechanical process at the meniscus has been explored. During ADDC, the fluid flows involve capillary flow induced by non-uniform solvent evaporation, Marangoni flow caused by a surface tension gradient, and Couette flow driven by substrate movement. ${ }^{29,36,37} \mathrm{~A}$ fundamental feature is the presence of a stagnation point, where the streamline is perpendicular to the solution surface, separating the fluid into the "upward flow region" and "recirculation flow region" (Fig. 3a). ${ }^{29}$ Modelling the fluid flow at the meniscus is 


\section{a}

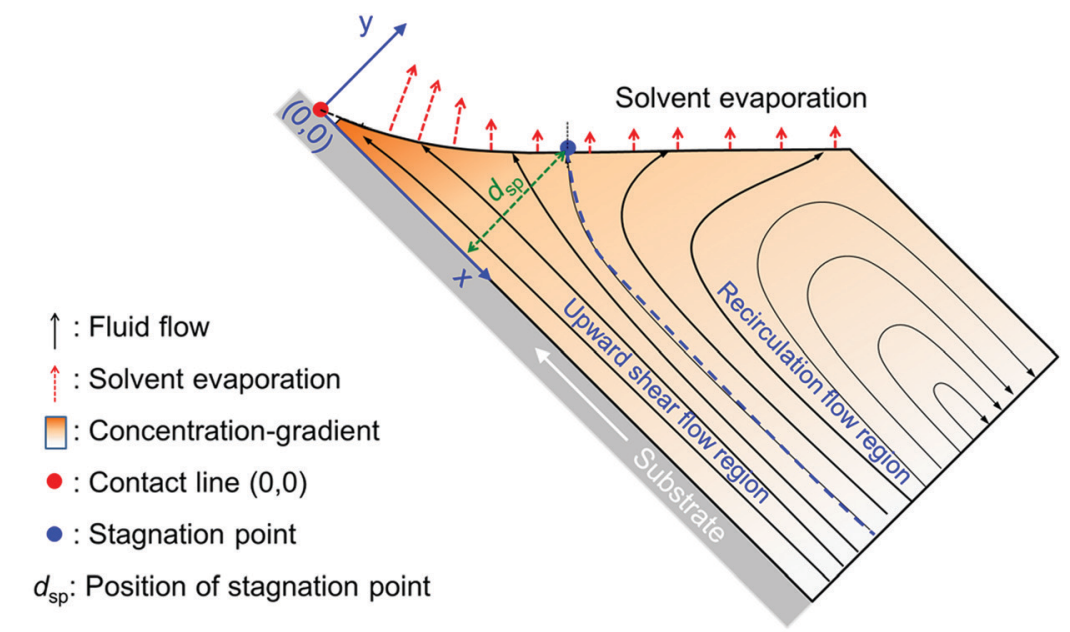

b

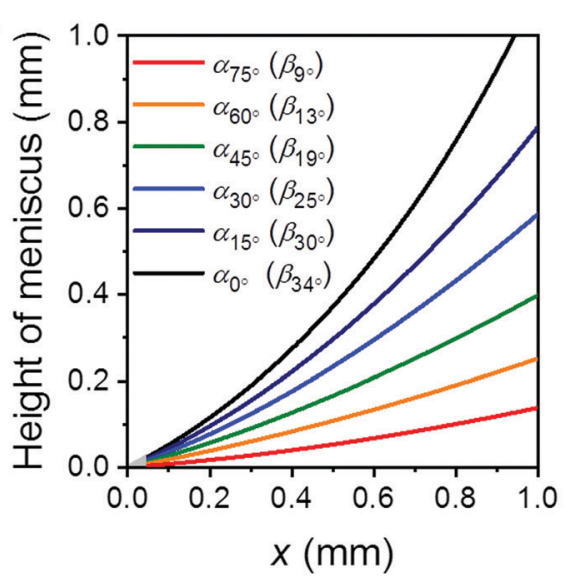

d

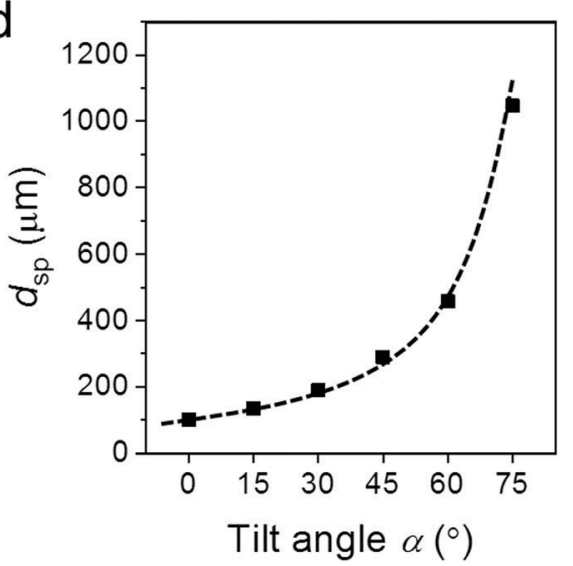

C
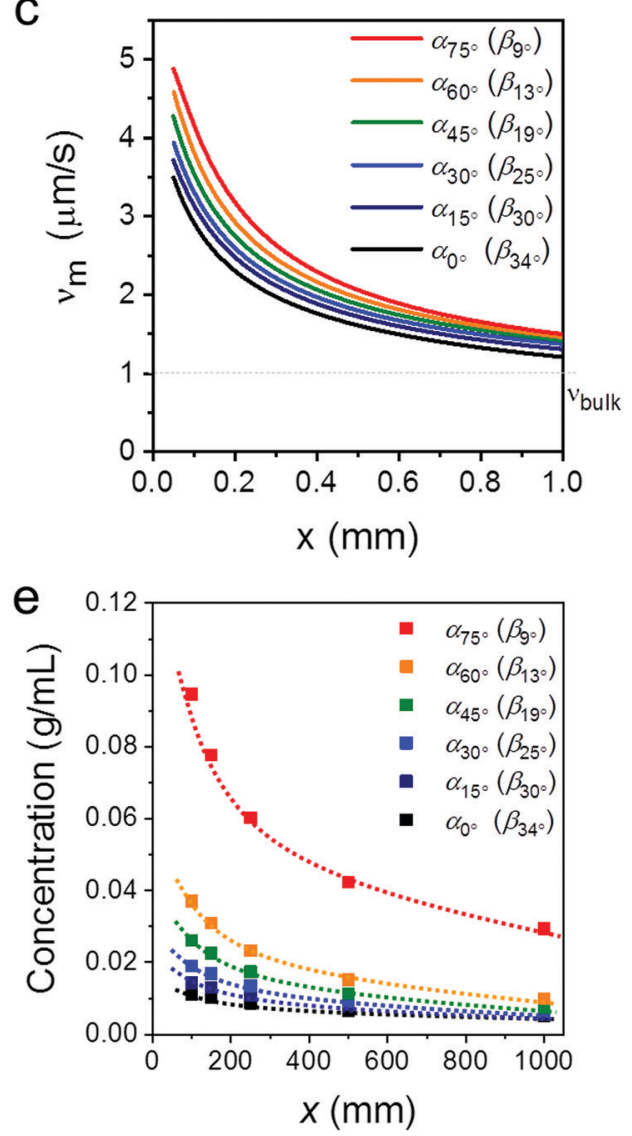

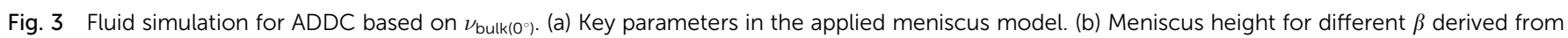
the optical images in Fig. S1b (ESI $\dagger$ ). (c) Evaporation rate $\left(\nu_{\mathrm{m}}\right)$ as a function of $x$. (d) Position of the stagnation point $\left(x_{\mathrm{sp}}\right)$ as a function of $\alpha$. (e) Solute concentration at the meniscus $\left(c_{\mathrm{m}}\right)$ as a function of $\alpha$.

challenging and includes various factors, such as the surface tension of the solution, surface energy of the substrate, and viscosity. ${ }^{30}$ Alternatively, we focus on the fundamental role of the meniscus shape in the fluid mechanical process and film growth. A two-dimensional fluid simulation was performed based on the Stokes flow, whereby the Marangoni effect is ignored (Fig. S5, ESI $\dagger$ ). All fluid simulations were performed in the evaporation regime at a dip-coating speed of $20 \mu \mathrm{m} \mathrm{s}^{-1}$.
The $x$-axis of the Cartesian coordinates represents the distance along the substrate from the contact line $(x)$, while the $y$-axis is related to the height perpendicular to the substrate (Fig. 3a). The meniscus shapes for different $\beta$ were derived from the optical images in Fig. S1b (ESI $\dagger$ ). The plots in Fig. 3b demonstrate that the meniscus height and $\beta$ decrease simultaneously, whereby for $\beta<15^{\circ}$ the meniscus height is less than $0.25 \mathrm{~mm}$ at $x<1 \mathrm{~mm}$ (Fig. 3b). 
The meniscus model for different geometries was established including the solvent evaporation, fluid flow, and concentration gradient (Fig. 3a). As the evaporation rate at the meniscus $\left(\nu_{\mathrm{m}}\right)$ is influenced by $\nu_{\text {bulk }}$ and the meniscus shape, ${ }^{38,39}$ assuming $\nu_{\operatorname{bulk}(\alpha)}=\nu_{\operatorname{bulk}\left(0^{\circ}\right)}, \nu_{\mathrm{m}}$ for different $\beta$ is calculated to reveal the role of the meniscus shape in evaporation. Fig. 3c demonstrates that $\nu_{\mathrm{m}}$ increases with the decrease of $x$ to a much higher extent

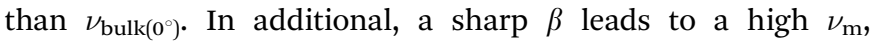
resulting from a thin meniscus. At the same time, the distance of the stagnation point $\left(d_{\mathrm{sp}}\right)$ shifts away from the substrate from $100 \mu \mathrm{m}$ to $1000 \mu \mathrm{m}$ when $\beta$ declines from $33.5^{\circ}$ to $9^{\circ}$ (Fig. $3 \mathrm{c}$ and Fig. S6, ESI $\dagger$ ). The shift of the stagnation point contributes to a wider upward flow region that transports more solute to the meniscus and contact line. This simulation demonstrates that a small $\beta$ leads to a high $\nu_{\mathrm{m}}$ and an upward flow and in this way induces a larger concentration gradient at the meniscus (Fig. 3d and Fig. S6, ESI $\dagger)$. For instance, at $x=0.1 \mathrm{~mm}$, the solute concentration $\left(c_{\mathrm{m}}\right)$ at $\beta_{13^{\circ}}\left(\alpha_{60^{\circ}}\right)$ is 2 and 3.5 times higher than at $\beta_{25^{\circ}}\left(\alpha_{30^{\circ}}\right)$ and $\beta_{34^{\circ}}\left(\alpha_{0^{\circ}}\right)$, respectively (Fig. 3e). Due to the raised $c_{\mathrm{m}}$ caused by the small $\beta$, C8-BTBT is more prone to saturate and nucleate at the contact line. ${ }^{40}$

The fluid simulation for different $\alpha$ (and $\beta$ ) was also performed for varied $\nu_{\operatorname{bulk}(\alpha)}$ conditions to compare with the experimental data obtained for ADDC of C8-BTBT. As shown in Fig. S6 (ESI $\dagger$ ), besides the contribution of small $\beta$, the gradually larger $\nu_{\operatorname{bulk}(\alpha)}$ additionally increases $\nu_{\mathrm{m}}$ and intensifies the upward flow, contributing to a higher $c_{\mathrm{m}}$. For instance, at $x=0.1 \mathrm{~mm}, c_{\mathrm{m}}$ at $\beta_{13^{\circ}}$ based on $\nu_{\operatorname{bulk}(\alpha)}$ is around 2 times that based on $\nu_{\text {bulk }\left(0^{\circ}\right)}$ (Fig. S7, ESI $\dagger$ ).

ADDC was also performed from a larger container $(50 \mathrm{~mL})$ completely filled by the solution to achieve the same $\nu_{\text {bulk, }}$, excluding the influence of varied $\nu_{\text {bulk }}$ under the experimental conditions (Fig. S8, ESI $\dagger$ ). Due to extensive material consumption, these experiments were performed for two representative cases. C8-BTBT and polystyrene $(400 \mathrm{kDa})$ were dip-coated at $200 \mu \mathrm{m} \mathrm{s}^{-1}$ and $80 \mu \mathrm{m} \mathrm{s}^{-1}$, respectively. Higher film thicknesses of C8-BTBT and polystyrene were obtained at greater $\alpha$, where the increased mass deposition results solely from small $\beta$ (Fig. S8b and c, ESI $\dagger$ ). These results directly confirm the role of the meniscus shape in the mass deposition during MGC.

\section{Impact of the substrate surface energy}

The OSC crystallization during MGC is more complex, including not only the fluid flow, but also the supersaturated concentration as the driving force and barrier for crystal nucleation and growth. The crystallization behavior of OSCs greatly depends on the substrate roughness and surface energy of the substrate, concentration and solubility. ${ }^{21}$ For instance, the nucleation barrier for two-dimensional spherulite heterogeneous nucleation in solution deposited films, $\Delta G_{\text {het }}{ }^{*}$, is determined by the concentration $(c)$, solubility $(\delta)$, temperature $(T)$, and surface energy between the solution and the crystals $\left(\gamma_{\mathrm{CL}}\right)$, as shown in eqn $(1)^{41}$

$$
\Delta G_{\mathrm{het}}{ }^{*}=\frac{-16 \pi^{3} r_{\mathrm{CL}}{ }^{3}}{3\left(k_{\mathrm{B}} T\right)^{3}\left(\ln \left(\frac{c}{\delta}\right)\right)^{2}} f(\vartheta)
$$

where $k_{\mathrm{B}}$ is Boltzmann's constant, and the shape factor $f(\vartheta)$ is influenced by the surface energy of the substrate.

To deeper understand the role of the meniscus shape in OSC crystallization, the influence of the surface energy on film coating of C8-BTBT was studied. The modulation of the surface energy was achieved by plasma treatment and self-assembly monolayer modification of the substrate using hexamethyldisilazane (HMDS) and octadecyltrichlorosilane (OTS), whose surface energy can be estimated by combining the equation of state with the Young equation. ${ }^{21}$ Details on the contact angle measurements are shown in Table S1 (ESI $\dagger$ ). As presented in Fig. 4a (ESI $\dagger)$, the surface energy for the bare $\mathrm{SiO}_{2}$ surface $\left(S_{\text {bare }}\right)$ is around $51.5 \mathrm{mN} \mathrm{m}^{-1}$ and for $S_{\text {plasma }}$ it is $67 \mathrm{mN} \mathrm{m}^{-1}$. However, HMDS and OTS modifications ( $S_{\text {HMDS }}$ and $S_{\text {OTS }}$ ) decrease the surface energy to 36.5 and $21 \mathrm{mN} \mathrm{m}^{-1}$, respectively (Fig. 4a). ${ }^{21,42}$

The meniscus angle of water $\left(\beta_{\text {water }}\right)$ at $\alpha_{0^{\circ}}$ increases from $31^{\circ}$ to $88^{\circ}$ when the surface energy declines from 67 to $21 \mathrm{mN} \mathrm{m}^{-1}$ (Fig. 4a and Fig. S9a, ESI $\dagger$ ). This trend corresponds to the surface energy dependent contact angle of water $\left(\theta_{\text {water }}\right)$. In contrast to $\beta_{\text {water, }} \beta_{\mathrm{CHCl}_{3}}$ remains at around $33^{\circ}-35.5^{\circ}$ for the same surface energy range (Fig. $4 \mathrm{~b}$ and Fig. S9b, ESI $\dagger$ ). The surface energy independent behavior of $\beta_{\mathrm{CHCl}_{3}}$ is due to the much lower surface tension of $\mathrm{CHCl}_{3}\left(26.7 \mathrm{mN} \mathrm{m}^{-1}\right)$ compared to water $\left(72.7 \mathrm{mN} \mathrm{m}^{-1}\right)$. However, the coverage ratio and crystallization of C8-BTBT during coating at $\alpha_{0^{\circ}}$ and $20 \mu \mathrm{m} \mathrm{s}^{-1}$ significantly rely on the surface energy of the substrate. The coverage is reduced for small surface energy, which is also related to morphology changes in the film (Fig. 4c). For instance, at $\alpha_{0^{\circ}}$ the dendritic C8-BTBT crystals on $S_{\text {plasma }}$ are much wider than those on $S_{\text {bare }}$, but almost no nucleation occurs on $S_{\text {HMDS }}$ and $S_{\mathrm{OTS}}$ (Fig. S10a, ESI $\dagger$ ). For substrates with different surface energy, $\beta_{\mathrm{CHCl}_{3}}$ shows a similar trend of decrease when $\alpha$ changes from $0^{\circ}$ to $30^{\circ}$ and $60^{\circ}$ (Fig. $4 \mathrm{~b}$ ). The declined $\beta_{\mathrm{CHCl}_{3}}$ leads to a higher coverage of C8-BTBT on $S_{\text {plasma }}$ and $S_{\text {bare }}$, but does not efficiently improve the crystallization on $S_{\mathrm{HMDS}}$ and $S_{\mathrm{OTS}}$ (Fig. $4 \mathrm{c}$ and Fig. S10b, ESI $\dagger$ ). Therefore, in the case of a similar $\beta$ during MGC, the crystallization of the OSC still significantly depends on the surface energy of the substrate. Differences in the crystallization behavior are attributed to the surface energy dependent nucleation barrier, which decreases in the order $\Delta G_{\mathrm{OTS}^{*}}{ }^{*}$ $\Delta G_{\text {HMDS }^{*}}>\Delta G_{\text {bare }}{ }^{*}>\Delta G_{\text {plasma }}{ }^{*}$ (Fig. 4d). ${ }^{43,44}$ These results indicate that the fluid flow assisted crystallization on a substrate with low surface energy is weakened by the high nucleation barrier (Fig. 4d). ${ }^{43}$

To facilitate the fluid flow assisted crystallization on a low surface energy substrate, a mixed-solvent $\left(\mathrm{CHCl}_{3}\right.$ : hexane $\left.4: 1\right)$ was introduced to reduce the solubility of C8-BTBT and thus to improve the supersaturation (Fig. S10c, ESI $\dagger$ ). The meniscus angle of the mixed-solvent $\left(\beta_{\text {mix }}\right)$ is also independent of the surface energy of the substrate. At the same $\alpha, \beta_{\text {mix }}$ is slightly lower than $\beta_{\mathrm{CHCl}_{3}}$, resulting from the smaller surface tension of hexane $\left(18.4 \mathrm{mN} \mathrm{m}^{-1}\right)$, as shown in Fig. $4 \mathrm{~b}$ and Fig. S9c (ESI $\dagger$ ). When dip-coated at $\alpha_{0}$ and $20 \mu \mathrm{m} \mathrm{s}^{-1}$ from the mixed-solvent, C8-BTBT exhibits dendritic morphologies with low coverage on $S_{\text {plasma }}, S_{\text {bare }}$, and $S_{\text {HMDS }}$ (Fig. S8b, ESI $\dagger$ ). The coverage of 
a

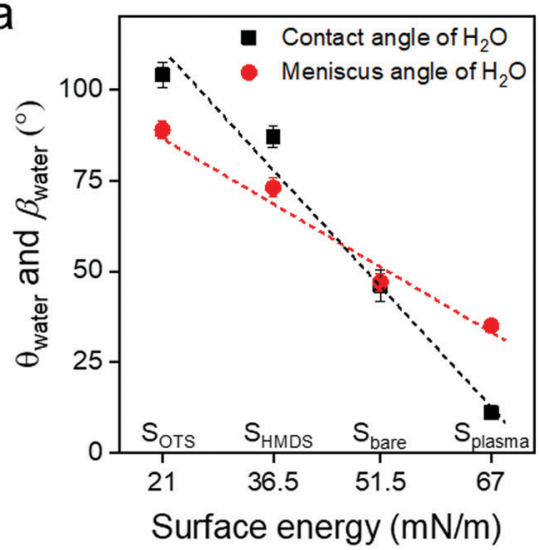

C

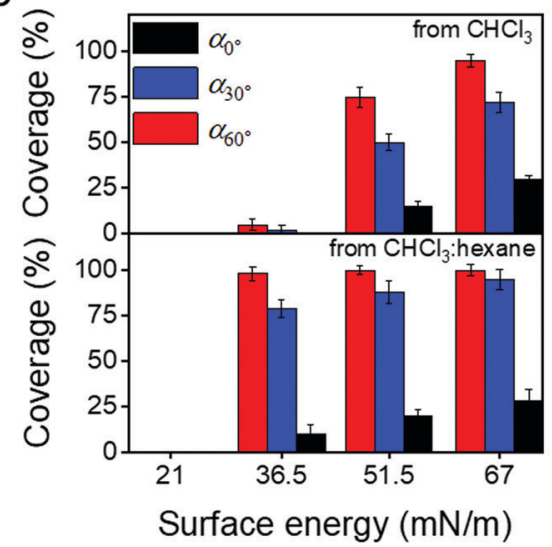

b

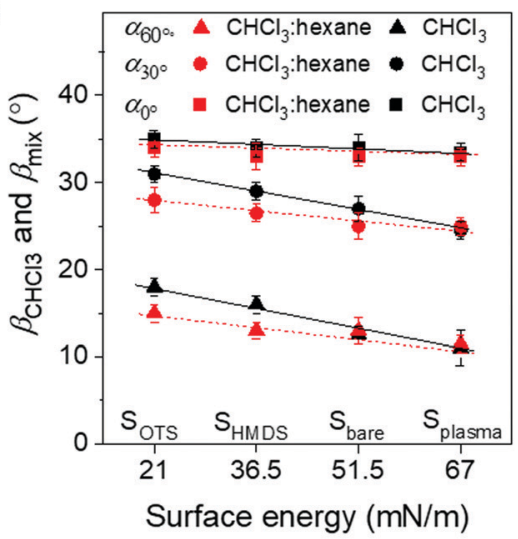

d

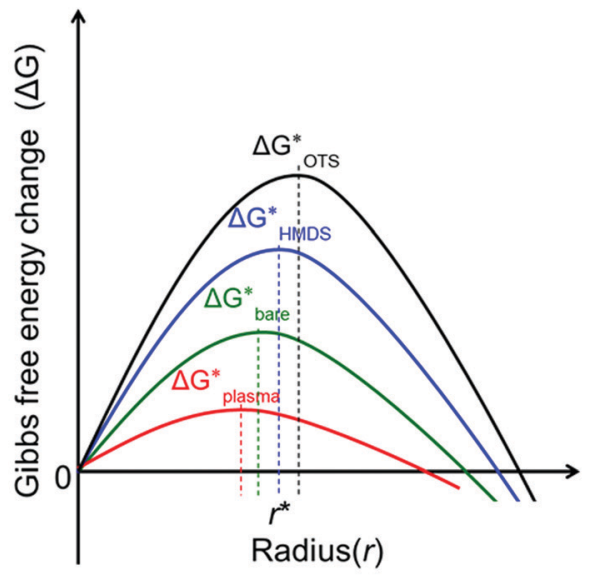

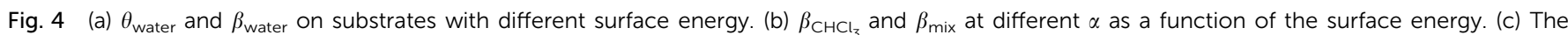

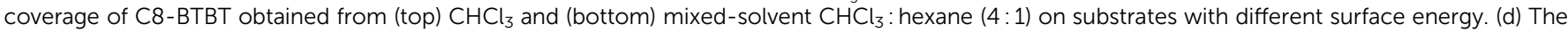

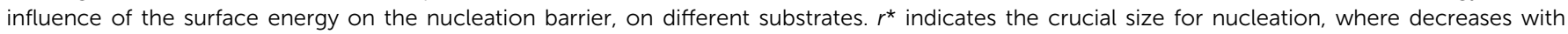
the increase of $r$ when $r>r^{*}$.

C8-BTBT greatly enhances at larger $\alpha$ and reaches above 95\% at $\alpha_{60^{\circ}}$ (Fig. 4c). This coverage improvement at large $\alpha$ (small $\beta$ ) is directly attributed to the increased upward flow and the reduced solubility, leading to higher supersaturation being necessary to overcome the nucleation barrier on $S_{\text {HMDs }}$. This means that to some extent the fluid flow assisted crystallization is facilitated by the raised supersaturation (Fig. S10c, ESI $\dagger$ ). However, even under the same deposition conditions no nucleation occurs on $S_{\text {OTS }}$, which may require a much higher supersaturation of C8-BTBT for nucleation on this type of surface during dip-coating. Because of this reason, the substrate surface modification by self-assembled monolayers of moderate surface energy provides the appropriate requirements for excellent mobility OFETs through the improvement of the crystallization during MGC at small $\beta$ and reduction of the trap density at the interface.

\section{Molecular packing and charge carrier transport}

To study the packing of C8-BTBT in the dip-coated films, grazing incidence wide-angle X-ray scattering (GIWAXS) was performed. The GIWAXS patterns of dip-coated C8-BTBT films indicate identical molecular packing in films cast at $20 \mu \mathrm{m} \mathrm{s}^{-1}$ from $\mathrm{CHCl}_{3}$ at $\alpha_{0^{\circ}}, \alpha_{30^{\circ}}$, and $\alpha_{60^{\circ}}$ on $\mathrm{S}_{\text {plasma }}$ (Fig. S11a-c, ESI $\dagger$ ). The distinct out-of-plane scattering intensity at $q_{z}=0.22 \AA^{-1}$ for $q_{x y}=0 \AA^{-1}$ is assigned to an interlayer distance of $2.85 \mathrm{~nm}$, corresponding to the step-height of the terrace-like morphology observed by AFM (Fig. 1e and Fig. S2a, ESI $\dagger$ ). The in-plane reflection at $q_{\mathrm{z}}=0 \AA^{-1}$ and $q_{x y}=1.90 \AA^{-1}$ is associated with a $\pi$-stacking distance of $0.33 \mathrm{~nm}$, which is characteristic for preferential edge-on organization of the molecules towards the surface, where the long molecular axis is parallel to the out-of-plane direction (Fig. 5a). ${ }^{45}$ The higher reflection intensity at $\alpha_{60}$ is related to the greater film thickness, whereas the low intensity at $\alpha_{0}$ is attributed to the low surface coverage.

To probe the charge carrier transport of C8-BTBT obtained by ADDC, bottom-gate and top-contact transistors were fabricated, where the channel length $(25 \mu \mathrm{m})$ was parallel to the coating direction (Fig. 5a). The average charge carrier mobilities of crystalline C8-BTBT films dip-coated on $\mathrm{S}_{\text {plasma }}$ increase with larger $\alpha$ for different dip-coating speeds (Fig. 5b). As derived from the transfer curves, the transistors show a pronounced $I_{\text {on }} / I_{\text {off }}$ ratio of around $10^{7}-10^{8}$ (Fig. S11d-f, ESI $\dagger$ ). When dipcoated at $200 \mu \mathrm{m} \mathrm{s}^{-1}$, dendritic crystals and a low coverage ratio of C8-BTBT lead to a mobility of less than $0.2 \mathrm{~cm}^{2} \mathrm{~V}^{-1} \mathrm{~s}^{-1}$ 
a

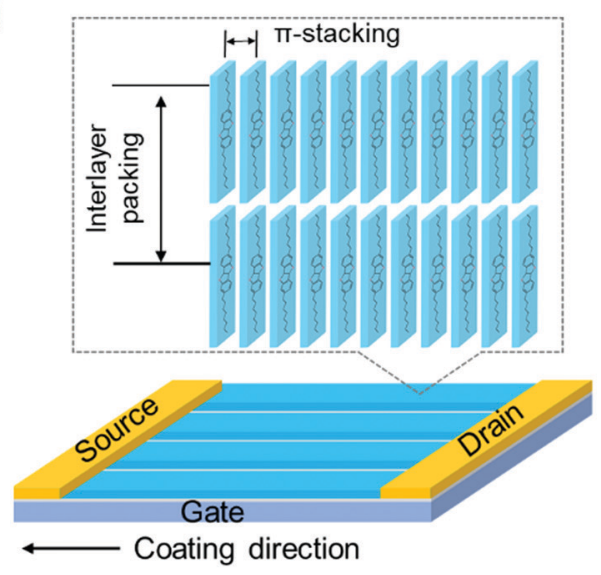

C

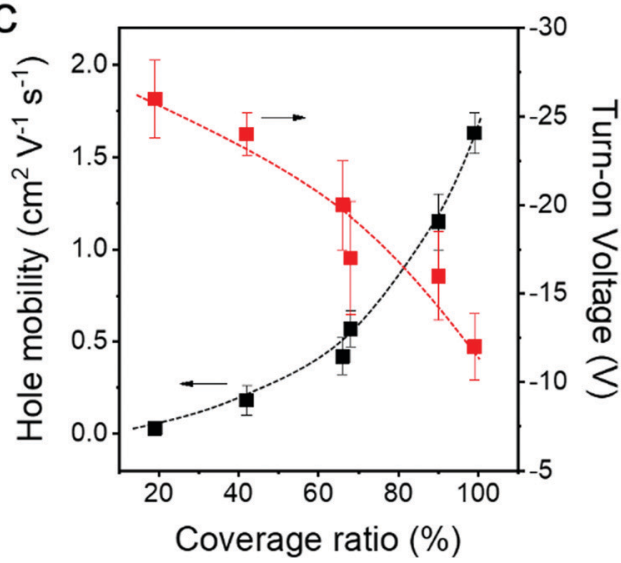

b

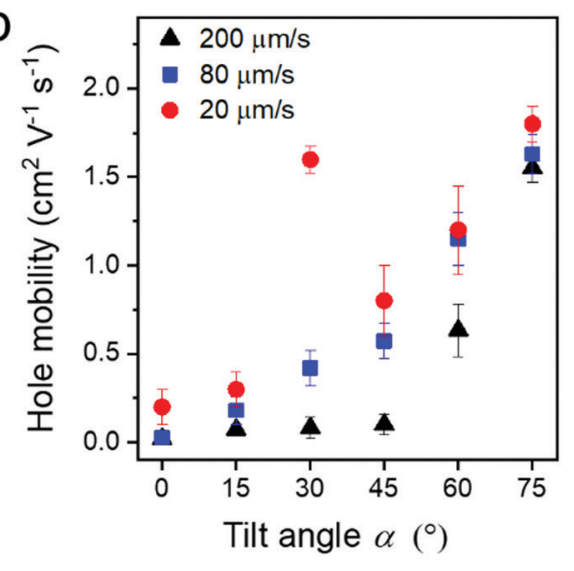

d

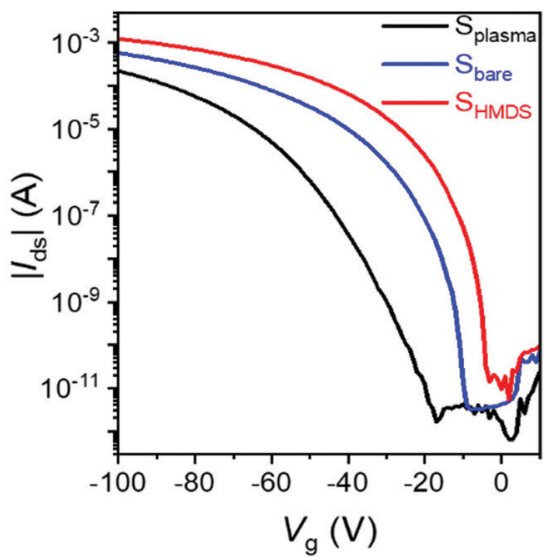

Fig. 5 (a) Schematic of C8-BTBT packing in the dip-coated OFETs. (b) Average mobilities of C8-BTBT on $\mathrm{S}_{\text {plasma }}$ dip-coated from $\mathrm{CHCl}_{3}$ at different speeds as a function of $\alpha$. (c) Relation between the hole mobility, turn-on voltage, and coverage ratio for C8-BTBT on $\mathrm{S}_{\text {plasma }}$ from $\mathrm{CHCl}_{3}$ at $80 \mu \mathrm{m} \mathrm{s} \mathrm{s}^{-1}$ and various $\alpha$. (d) Transfer curves at $V_{\mathrm{ds}}=-100 \mathrm{~V}$ for C8-BTBT on different substrates from the mixed-solvent at $20 \mu \mathrm{m} \mathrm{s} \mathrm{s}^{-1}$ and $\alpha_{60^{\circ}}$.

at $\alpha<45^{\circ}$, which improves for $\alpha>60^{\circ}$ (Fig. 5b and Fig. S11d, ESI $\dagger$ ). At a deposition speed of $80 \mu \mathrm{m} \mathrm{s} \mathrm{s}^{-1}$, the mobilities gradually rise from $0.03 \mathrm{~cm}^{2} \mathrm{~V}^{-1} \mathrm{~s}^{-1}$ to $1.5 \mathrm{~cm}^{2} \mathrm{~V}^{-1} \mathrm{~s}^{-1}$ with larger tilt angle $\alpha$ (Fig. $5 \mathrm{~b}$ and Fig. S11e, ESI $\dagger$ ). At the same time, the turn-on voltage is reduced from $-25 \mathrm{~V}$ to around $-15 \mathrm{~V}$. At $20 \mu \mathrm{m} \mathrm{s}^{-1}$, the mobility also increases from $0.2 \mathrm{~cm}^{2} \mathrm{~V}^{-1} \mathrm{~s}^{-1}$ to $1.8 \mathrm{~cm}^{2} \mathrm{~V}^{-1} \mathrm{~s}^{-1}$ for $\alpha$ from $0^{\circ}$ to $75^{\circ}$, except the extraordinary high upwards outlier of $1.6 \mathrm{~cm}^{2} \mathrm{~V}^{-1} \mathrm{~s}^{-1}$ at $\alpha_{30^{\circ}}$ (Fig. $5 \mathrm{~b}$ and Fig. S11f, ESI $\dagger$ ). This value, found only for $\alpha_{30^{\circ}}$ and $20 \mu \mathrm{m} \mathrm{s}^{-1}$, results from the well aligned crystalline structures (Fig. 2). This confirms the common knowledge that both high coverage ratio and pronounced alignment of crystalline films are important for the charge transport in OFETs. ${ }^{4}$ For instance, superior charge carrier mobilities were obtained for high coverage of C8-BTBT bar-coated from mixed solvents on a wettable surface. ${ }^{46}$ Fig. $5 \mathrm{c}$ depicts the charge carrier mobility and turn-on voltage as a function of the coverage ratio for C8-BTBT films cast at $80 \mu \mathrm{m} \mathrm{s}^{-1}$. Thereby, the coverage ratio varies with $\alpha$ as discussed for Fig. 1g. Both transistor parameters improve for higher coverage ratios. The charge carrier mobility slightly increases by taking into account the coverage ratio in the calculation of the device parameters (Fig. S12, ESI $\dagger$ ). The decrease in turn-on voltage with higher coverage ratio at larger $\alpha$ is attributed to a homogenous film morphology with less domain boundaries, which typically act as trapping sites for charge carriers.

Surface modification can also favor the charge carrier transport in OFETs. ${ }^{42}$ The transfer curves in Fig. $5 \mathrm{~d}$ reveal that the average mobility rises from $1.5 \mathrm{~cm}^{2} \mathrm{~V}^{-1} \mathrm{~s}^{-1}$ for $\mathrm{S}_{\text {plasma to }}$ $2.0 \mathrm{~cm}^{2} \mathrm{~V}^{-1} \mathrm{~s}^{-1}$ for $S_{\text {bare }}$ and to $2.7 \mathrm{~cm}^{2} \mathrm{~V}^{-1} \mathrm{~s}^{-1}$ for $S_{\mathrm{HMDS}}$ when C8-BTBT is dip-coated from a mixed-solvent at $20 \mu \mathrm{m} \mathrm{s}^{-1}$ and $\alpha_{60^{\circ}}$. This improvement in device performance is attributed to the reduction of the surface trap density, ${ }^{47}$ and a slightly improved in-plane molecular order (Fig. S13, ESI $\dagger$ ) due to the self-assembled monolayer applied at the interface. On all three types of surfaces the C8-BTBT molecules are edge-on arranged as evident from the in-plane (100) and (010) and out-of-plane (001) reflections in the GIWAXS pattern (Fig. S14, ESI $\dagger$ ). ${ }^{32}$ The highest mobility of around $3.6 \mathrm{~cm}^{2} \mathrm{~V}^{-1} \mathrm{~s}^{-1}$ is obtained for $S_{\mathrm{HMDS}}$ at $20 \mu \mathrm{m} \mathrm{s}^{-1}$ and $\alpha_{60^{\circ}}$ which corresponds to an average performance of C8-BTBT. ${ }^{48}$ Notably, the small $\beta$ and low solubility of C8-BTBT in the mixed-solvent significantly favor the crystallization of the organic semiconductor during ADDC, improving the device performance. It is assumed that the charge carrier mobility of dip-coated C8-BTBT can be further 
improved by blending with thermoplastic polymers to optimize the film morphology. ${ }^{49,50}$

\section{Conclusions}

In this work, we have demonstrated the crucial role of the meniscus shape in the fluid flow and crystallization of a small molecule OSC during MGC. Through controlling the meniscus shape by ADDC, we found that the increased upward flow at small $\beta$ enlarges the concentration gradient at the meniscus, yielding raised supersaturation and mass deposition of the OSC. On the other hand, at low surface energy of the substrate the fluid flow assisted crystallization at small $\beta$ is suppressed by an elevated nucleation barrier. The resulting aligned film morphologies and higher surface coverage significantly enhance the charge carrier transport in the dip-coated C8-BTBT films. These results provide new insights into the crystallization mechanism of OSCs during MGC. The control of the meniscus shape is a convenient and efficient way to modulate the crystallization of OSCs for improving their film deposition by MGC. This is an important aspect since a variety of OSCs encounter enormous challenges in the deposition of well-ordered and homogeneous films. The understanding of the correlation between crystallization and fluid mechanics is also crucial for scaling-up the solution processing of OSCs towards practical applications.

\section{Conflicts of interest}

There are no conflicts to declare.

\section{Acknowledgements}

K. Zhang thanks the China Scholarship Council (CSC) for financial support. M. Borkowski and T. Marszalek acknowledge the Foundation for Polish Science financed by the European Union under the European Regional Development Fund (POIR.04.04.00-00-3ED8/17-01). W. Pisula acknowledges the National Science Centre, Poland, through the grant UMO-2015/ 18/E/ST3/00322. Z. Wang and G. Fytas acknowledge the financial support by ERC AdG SmartPhon (Grant No. 694977). Open Access funding provided by the Max Planck Society.

\section{Notes and references}

1 H. Dong, X. Fu, J. Liu, Z. Wang and W. Hu, Adv. Mater., 2013, 25, 6158-6183.

2 H. Sirringhaus, Adv. Mater., 2014, 26, 1319-1335.

3 S. Wang, J. Xu, W. Wang, G.-J. N. Wang, R. Rastak, F. Molina-Lopez, J. W. Chung, S. Niu, V. R. Feig, J. Lopez, T. Lei, S.-K. Kwon, Y. Kim, A. M. Foudeh, A. Ehrlich, A. Gasperini, Y. Yun, B. Murmann, J. B.-H. Tok and Z. Bao, Nature, 2018, 555, 83-88.

4 Y. Diao, L. Shaw, Z. Bao and S. C. B. Mannsfeld, Energy Environ. Sci., 2014, 7, 2145-2159.

5 X. Zhang, J. Jie, W. Deng, Q. Shang, J. Wang, H. Wang, X. Chen and X. Zhang, Adv. Mater., 2016, 28, 2475-2503.
6 (a) X. Gu, L. Shaw, K. Gu, M. F. Toney and Z. Bao, Nat. Commun., 2018, 9, 534; (b) M. Richard, A. Al-Ajaji, S. Ren, A. Foti, J. Tran, M. Frigoli, B. Gusarov, Y. Bonnassieux, E. G. Caurel, P. Bulkin, R. Ossikovski and A. Yassar, Adv. Colloid Interface Sci., 2020, 275, 102080.

7 S. Wang, W. Pisula and K. Müllen, J. Mater. Chem., 2012, 22, 24827-24831.

8 W. Pisula, A. Menon, M. Stepputat, I. Lieberwirth, U. Kolb, A. Tracz, H. Sirringhaus, T. Pakula and K. Müllen, Adv. Mater., 2005, 17, 684-689.

9 M. R. Niazi, R. Li, E. Q. Li, A. R. Kirmani, M. Abdelsamie, Q. Wang, W. Pan, M. M. Payne, J. E. Anthony, D.M. Smilgies, S. T. Thoroddsen, E. P. Giannelis and A. Amassian, Nat. Commun., 2015, 6, 8598.

10 Y. Diao, B. C.-K. Tee, G. Giri, J. Xu, D. H. Kim, H. A. Becerril, R. M. Stoltenberg, T. H. Lee, G. Xue, S. C. B. Mannsfeld and Z. Bao, Nat. Mater., 2013, 12, 665-671.

11 D. Grosso, J. Mater. Chem., 2011, 21, 17033-17038.

12 M. Li, C. An, T. Marszalek, I. Lieberwirth, M. Baumgarten, K. Müllen and W. Pisula, Adv. Mater., 2016, 28, 2245-2252. 13 M. Li, D. K. Mangalore, J. B. Zhao, J. H. Carpenter, H. P. Yan, H. Ade, H. Yan, K. Müllen, P. W. M. Blom, W. Pisula, D. M. de Leeuw and K. Asadi, Nat. Commun., 2018, 9, 451.

14 G. Qu, J. J. Kwok and Y. Diao, Acc. Chem. Res., 2016, 49, 2756-2764.

15 A. Tracz, T. Makowski, S. Masirek, W. Pisula and Y. H. Geerts, Nanotechnology, 2007, 8, 485303.

16 J. Jang, S. Nam, K. Im, J. Hur, S. N. Cha, J. Kim, H. B. Son, H. Suh, M. A. Loth, J. E. Anthony, J.-J. Park, C. E. Park, J. M. Kim and K. Kim, Adv. Funct. Mater., 2012, 22, 1005-1014.

17 G. Giri, E. Verploegen, S. C. B. Mannsfeld, S. Atahan-Evrenk, D. H. Kim, S. Y. Lee, H. A. Becerril, A. Aspuru-Guzik, M. F. Toney and Z. Bao, Nature, 2011, 480, 504-508.

18 R. Janneck, F. Vercesi, P. Heremans, J. Genoe and C. Rolin, Adv. Mater., 2016, 28, 8007-8013.

19 J. Chang, C. Chi, J. Zhang and J. Wu, Adv. Mater., 2013, 25, 6442-6447.

20 S. Park, G. Giri, L. Shaw, G. Pitner, J. Ha, J. H. Koo, X. Gu, J. Park, T. H. Lee, J. H. Nam, Y. Hong and Z. Bao, Proc. Natl. Acad. Sci. U. S. A., 2015, 112, 5561-5566.

21 F. Zhang, E. Mohammadi, X. Luo, J. Strzalka, J. Mei and Y. Diao, Langmuir, 2018, 34, 1109-1122.

22 G. De Luca, W. Pisula, D. Credgington, E. Treossi, O. Fenwick, G. M. Lazzerini, R. Dabirian, E. Orgiu, A. Liscio, V. Palermo, K. Müllen, F. Cacialli and P. Samori, Adv. Funct. Mater., 2011, 21, 1279-1295.

23 M. Li, C. An, W. Pisula and K. Müllen, Small, 2014, 10, 1926-1931.

24 D. R. Ceratti, B. Louis, X. Paquez, M. Faustini and D. Grosso, Adv. Mater., 2015, 27, 4958-4962.

25 E. Mohammadi, C. Zhao, Y. Meng, G. Qu, F. Zhang, X. Zhao, J. Mei, J.-M. Zuo, D. Shukla and Y. Diao, Nat. Commun., 2017, 8, 16070.

26 W. Deng, X. Zhang, H. Dong, J. Jie, X. Xu, J. Liu, L. He, L. Xu, W. Hu and X. Zhang, Mater. Today, 2019, 24, 17-25. 
27 N. J. Arfsten, A. Eberle, J. Otto and A. Reich, J. Sol-Gel Sci. Technol., 1997, 8, 1099-1104.

28 T. Bottein, J. Loizillon and D. Grosso, J. Phys. Chem. B, 2017, 121, 6220-6225.

29 A. Filali, L. Khezzar and E. Mitsoulis, Comput. Fluids, 2013, 82, 110-121.

30 K. Zhang, T. Marszalek, P. Wucher, Z. Y. Wang, L. Veith, H. Lu, H. J. Räder, P. M. Beaujuge, P. W. M. Blom and W. Pisula, Adv. Funct. Mater., 2018, 28, 1805594.

31 Z. Chai, S. A. Abbasi and A. A. Busnaina, ACS Appl. Mater. Interfaces, 2018, 10, 18123-18130.

32 S. Kwon, J. Kim, G. Kim, K. Yu, Y.-R. Jo, B.-J. Kim, J. Kim, H. Kang, B. Park and K. Lee, Adv. Mater., 2015, 27, 6870-6877.

33 M. Chen, B. Peng, S. Huang and P. K. L. Chan, Adv. Funct. Mater., 2020, 30, 1905963.

34 P. Born, S. Blum, A. Munoz and T. Kraus, Langmuir, 2011, 27, 8621-8633.

35 H. Bodiguel, F. Doumenc and B. Guerrier, Langmuir, 2010, 26, 10758-10763.

36 B. B. Patel and Y. Diao, Nanotechnology, 2018, 29, 044004.

37 C. Hsueh, F. Doumenc and B. Guerrier, Eur. Phys. J.: Spec. Top., 2013, 219, 51-57.

38 R. D. Deegan, O. Bakajin, T. F. Dupont, G. Huber, S. R. Nagel and T. A. Witten, Nature, 1997, 389, 827-829.

39 R. D. Deegan, Phys. Rev. E: Stat. Phys., Plasmas, Fluids, Relat. Interdiscip. Top., 2000, 61, 475-485.
40 O. Goto, S. Tomiya, Y. Murakami, A. Shinozaki, A. Toda, J. Kasahara and D. Hobara, Adv. Mater., 2012, 24, 1117-1122.

41 N. T. Thanh, N. Maclean and S. Mahiddine, Chem. Rev., 2014, 114, 7610-7630.

42 S. C. Lim, S. H. Kim, J. H. Lee, M. K. Kim, D. J. Kim and T. Zyung, Synth. Met., 2005, 148, 75-79.

43 J. R. Ray, B. Lee, J. Baltrusaitis and Y. S. Jun, Environ. Sci. Technol., 2012, 46, 13167-13175.

44 Y. S. Jun, D. Kim and C. W. Neil, Acc. Chem. Res., 2016, 49, 1681-1690.

45 Y. D. Park, J. A. Lim, H. S. Lee and K. Cho, Mater. Today, 2007, 10, 46-54.

46 Z. Zhang, B. Peng, X. Ji, K. Pei and P. K. L. Chan, Adv. Funct. Mater., 2017, 27, 1703443.

47 L. L. Chua, J. Zaumseil, J. F. Chang, E. C. W. Ou, P. K. H. Ho, H. Sirringhaus and R. H. Friend, Nature, 2005, 434, 194-199.

48 R. Wawrzinek, J. Sobus, M. U. Chaudhry, V. Ahmad, A. Grosjean, J. K. Clegg, E. B. Namdas and S.-C. Lo, ACS Appl. Mater. Interfaces, 2019, 11, 3271-3279.

49 Y. Yuan, G. Giri, A. L. Ayzner, A. P. Zoombelt, S. C. B. Mannsfeld, J. Chen, D. Nordlund, M. F. Toney, J. Huang and Z. Bao, Nat. Commun., 2014, 5, 3005.

50 K. Haase, C. T. da Rocha, C. Hauenstein, Y. Zheng, M. Hambsch and S. C. B. Mannsfeld, Adv. Electron. Mater., 2018, 4, 1800076. 